\title{
Effects of feeding strategy on larval development of the Amazon River prawn Macrobrachium amazonicum
}

\author{
Mariana Cutolo de Araujo ${ }^{1 *}$, Wagner Cotroni Valenti2,3
}

\author{
${ }^{1}$ Universidade Federal do Recôncavo da Bahia, Centro de Ciências Agrárias, Ambientais e Biológicas, Cruz das Almas, BA, Brazil. \\ ${ }^{2}$ Universidade Estadual Paulista, Instituto de Biociências, São Vicente, SP, Brazil. \\ ${ }^{3}$ Universidade Estadual Paulista, Centro de Aquicultura, Jaboticabal, SP, Brazil.
}

\begin{abstract}
Effects of four feeding regimes on the development and feed intake, survival, productivity, and growth of Macrobrachium amazonicum larvae were investigated. Larvae were fed from stage II to IX, as follows: Artemia nauplii + inert diet during the entire larval cycle (AIn); Artemia nauplii for the entire larval cycle + inert diet from stage V onward (A/AIn); Artemia nauplii until stage IV + inert diet from stage IV onward (A/In); and only inert diet for the entire larval cycle (In). Each feeding regime (treatment) was carried out in three 50-L rectangular black tanks, set up in a recirculating system, filled with 10 salinity brackish water, and stocked at $81.8 \pm 0.8$ larvae/L. The larval stage index, occurrence of Artemia nauplii and/or inert feed into the digestive tract, survival (number of larvae and postlarvae), productivity (number of postlarvae/L), and weight gain (mg) were evaluated. Larval development was similar in treatments AIn, A/Ain, and A/In, but was delayed in treatment In. Artemia nauplii were ingested by larvae irrespective of developmental stages, while inert feed was ingested only from stage III onward. Survival and productivity were higher in treatment AIn and decreased according to the number of days larvae were fed Artemia nauplii. Macrobrachium amazonicum larvae are omnivorous and polytrophic, but live feed is essential in the first stages and act as a complementary diet in the last half of larval cycle. There is a potential for inert diet to replace Artemia in the last phase of development if the nutrient composition matches larvae requirements. The combination of Artemia nauplii and inert diet during all larval cycles is the best management to maximize productivity.
\end{abstract}

Key Words: prawn larvae, productivity, replacing of Artemia, stages, survival

\section{Introduction}

Macrobrachium amazonicum is the South American freshwater prawn with higher potential for culture (Kutty et al., 2000; Valenti, 2007; Moraes-Valenti and Valenti, 2010). It is largely consumed as feed in northern and northeastern Brazil. This species is hardy and easily bred and has rapid growth and a high survival rate in tanks and ponds (Moraes-Valenti and Valenti, 2010; Marques and Moraes-Valenti, 2012). Despite these advantages, there are many gaps in its technology. Thus, scientific investigation that focus on key points, such as feeding management in the hatchery phase, is necessary.

Received: April 2, 2015

Accepted: October 30, 2016

*Corresponding author: mcarcino@ufrb.edu.br

http://dx.doi.org/10.1590/S1806-92902017000200001

How to cite: Araujo, M. C. and Valenti, W. C. 2017. Effects of feeding strategy on larval development of the Amazon River prawn Macrobrachium amazonicum. Revista Brasileira de Zootecnia 46(2):85-90

Copyright (C) 2017 Sociedade Brasileira de Zootecnia. This is an Open Access article distributed under the terms of the Creative Commons Attribution License (http://creativecommons.org/licenses/by/4.0/), which permits unrestricted use, distribution, and reproduction in any medium, provided the original work is properly cited.
Feeding strategy in crustacean larviculture should consider behavior, physiology, and nutritional requirements of the target species (Loya-Javellana, 1989; Sorgeloos and Léger, 1992; Lavens et al., 2000). These characteristics are scarcely known for M. amazonicum. In addition, feeding needs may change during larval development because freshwater prawn larvae develop through very distinct stages with different morphophysiological and behavioral characteristics.

The live feed most used in aquaculture hatchery is Artemia nauplii. Nevertheless, it has been demonstrated that it is not suitable for Macrobrachium rosenbergii larvae in the last developmental stages because of the small size (Barros and Valenti, 2003) and insufficient nutrients (Alam et al., 1995; Valenti et al., 2010). Thus, feed supplementation or replacement of Artemia by formulated diet is necessary (Kovalenko et al., 2002; Barros and Valenti, 2003). In addition, it is desirable to reduce the dependence on Artemia because of the high cost and shortage.

Currently, M. amazonicum larvae are fed live Artemia nauplii throughout the whole cycle plus inert diet from stage V onward (Moraes-Valenti and Valenti, 2010). Nevertheless, Araujo and Valenti (2007) found that larvae eat inert diet from stage III onward and the frequency of 
inert diet intake is higher than Artemia nauplii from stages VII to IX. These results suggest that Artemia nauplii might be replaced by inert feed from stage VII onward. However, Maciel and Valenti (2014a) observed substantial decrease in survival when only inert diet was supplied from larval stage VII onward. Thus, more information is necessary to establish the best feeding strategy for hatchery of M. amazonicum. Therefore, in this paper, four feeding strategies comprising different combinations of Artemia nauplii and inert diet during larval development were tested.

\section{Material and Methods}

Newly-hatched M. amazonicum larvae were obtained from ovigerous females in Jaboticabal, São Paulo, Brazil. The broodstock were obtained from the wild in northeastern

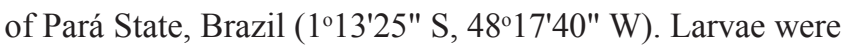
stocked in 12 black experimental tanks $(35 \times 35.5 \mathrm{~cm} \times$ $72.0 \mathrm{~cm}$ ) filled with $50 \mathrm{~L}$ of 10 salinity brackish water, at $81.8 \pm 0.8$ larvae/L. Black tanks reduce stress and improve M. amazonicum larval performance (Maciel and Valenti, 2014b). The larvae were fed from stage II to stage IX until reaching postlarvae. Larvae in stage I were lecithotrophic and did not feed (Araujo and Valenti, 2007; Anger and Hayd, 2009). The experiment lasted 20 days.

All the tanks had water temperature control, constant aeration, and individual biological filter operating in a closed recirculation system. Water quality was maintained within the normal range as recommended by Valenti et al. (2010) for M. rosenbergii. This was assured by siphoning the bottom of tanks daily. The temperature was monitored twice daily (morning and afternoon), whereas $\mathrm{pH}$, dissolved oxygen, salinity, concentration of ammonia (method described by Solorzano, 1969), and nitrite (method described by Strickland and Parsons, 1972) twice a week. Light:dark cycle was $12: 12$ with lights on at $06: 00 \mathrm{~h}$. Water temperature was $30.1 \pm 0.4{ }^{\circ} \mathrm{C} ; \mathrm{pH}, 8.0 \pm 0.1$; salinity,
10.3 \pm 0.3 ; ammonia-N, $75.7 \pm 9.7 \mu \mathrm{g} / \mathrm{L}$; nitrite-N, $57.3 \pm 7.2 \mu \mathrm{g} / \mathrm{L}$; and dissolved oxygen, $6.30 \pm 0.41 \mathrm{mg} / \mathrm{L}$.

This experiment was set up according to a completely randomized design with four treatments (feeding strategies; Table 1) and three replicates. Artemia was firstly offered at five nauplii/mL and then gradually increased up to 15 nauplii/mL at stage IX. Inert diet was offered at $0.4 \mathrm{mg} /$ day and then progressively increased to $1.8 \mathrm{mg}$ /day based on leftovers on the bottom.

The inert diet was humid and composed of $34 \%$ chicken egg, 10\% mussel, $10 \%$ marine fish, 4\% dried milk, $2 \%$ wheat flour, $0.8 \%$ cod liver oil, $1.4 \%$ vitamin and mineral supplement, and 37.8\% water (see Mallasen and Valenti, 1998 for details). The ingredients were weighed, mixed in a blender, and cooked in water bath to pudding consistency. Portions of the diet were stored frozen at $-18^{\circ} \mathrm{C}$ until required for feeding. The diet was weighed and sieved in an stainless steel sieve, $425-\mu \mathrm{m}$ mesh, before feeding. It has been demonstrated that the common practice of breaking the feed into variable size pellets during larval development of $M$. rosebergii is not necessary or effective (Barros and Valenti 2003). We assumed the same for M. amazonicum. Proximate composition of this diet was $45 \%$ crude protein, $22.6 \%$ ether extract, $23.6 \%$ nitrogenfree extract, $8.8 \%$ minerals, $18.3 \%$ original dry matter, and $4989 \mathrm{kcal} / \mathrm{kg}$ gross energy, following Mallasen and Valenti (1998).

Ten larvae were collected from each tank (three tanks for each feeding regime) periodically. These larvae were observed under stereomicroscope and larval stage was identified according to Guest (1979). Larval stage index (LSI) was calculated according to Manzi et al. (1977), as follows:

$$
L S I=\frac{\sum S_{i} \cdot n_{i}}{N}
$$

in which $S_{i}$ is the larval stage $(i=1-9) ; n_{i}$ is the number of larvae in stage $S_{\mathrm{i}}$, and $N$ is the total number of larvae observed.

Table 1 - Feeding strategies (treatments) throughout M. amazonicum larval development

\begin{tabular}{|c|c|c|c|c|c|c|c|c|c|}
\hline \multirow{2}{*}{ Treatment $^{1}$} & \multicolumn{9}{|c|}{ Larval developmental stage } \\
\hline & I & II & III & IV & $\mathrm{V}$ & VI & VII & VIII & IX \\
\hline $\mathrm{AIn}^{2,3}$ & - & $\mathrm{A}+\mathrm{In}$ & $\mathrm{A}+\mathrm{In}$ & $\mathrm{A}+\mathrm{In}$ & $\mathrm{A}+\mathrm{In}$ & $\mathrm{A}+\mathrm{In}$ & $\mathrm{A}+\mathrm{In}$ & $\mathrm{A}+\mathrm{In}$ & $\mathrm{A}+\mathrm{In}$ \\
\hline $\mathrm{A} / \mathrm{AIn}^{2,3}$ & - & A & A & A & $\mathrm{A}+\mathrm{In}$ & $\mathrm{A}+\mathrm{In}$ & $\mathrm{A}+\mathrm{In}$ & $\mathrm{A}+\mathrm{In}$ & $\mathrm{A}+\mathrm{In}$ \\
\hline $\mathrm{A} / \mathrm{In}^{2,4}$ & - & A & A & $\mathrm{A}+\mathrm{In}$ & In & In & In & In & In \\
\hline $\mathrm{In}^{4}$ & - & In & In & In & In & In & In & In & In \\
\hline
\end{tabular}

A - Artemia nauplii; In - inert feed.

${ }^{1}$ Three repetitions were performed for each treatment.

${ }^{2}$ Artemia supplied at 17:00 h.

${ }^{3}$ Inert feed supplied at $8: 30$ and $11: 30 \mathrm{~h}$.

${ }^{4}$ Inert feed supplied at 8:30,11:30, 14:30, 17:30, and 20:30 h. 
When $50 \%$ larvae in a tank reached the subsequent developmental stage, 10 individuals of each treatment were randomly sampled 15 min after the first feeding for determination of the gastrointestinal tract content (presence or absence of Artemia and inert diet). Each sampled larva was inspected under a stereomicroscope and feed ingested was classified into Artemia, inert diet, or Artemia + inert diet. Feed intake rate was calculated as the number of larvae ingesting a diet divided by the number of observed larvae and expressed as percentage.

On the 20th day after stocking, the experiment was finalized, survival was determined by counting live larvae and PL (postlarvae), and productivity was calculated as number of live PL/L. Dry mean weight of 300 larvae in stage I at the beginning of the experiment and of $50 \mathrm{PL}$ collected from each tank at the end of the experiment were determined. The animals were rinsed with distilled water, dried on filter paper, and transferred to 10 pre-weighed aluminum cartridges. The cartridges were placed into an oven $\left(60^{\circ} \mathrm{C}\right)$ for $24 \mathrm{~h}$ and then in a desiccator for $2 \mathrm{~h}$. The dried larvae were weighed to the nearest $1 \mu \mathrm{g}$ by means of a Mettler-Toledo balance.

Larval stage indexes and gastrointestinal tract content were evaluated by descriptive analyses. The survival and productivity data were compared among treatments using $G$-test (Sokal and Rohlf, 1995). Mean weight gain was compared among the treatments by parametric ANOVA ( $F$-test) followed by Tukey's test. Pearson's correlation coefficient (r) was used to test the correlation of survival and productivity with the number of days that larvae ate Artemia nauplii. For all statistical tests, significance level was set at $\mathrm{P}<0.05$. The data were analyzed using the SAS package (Statistical Analysis System, version 8.02).

\section{Results}

The larval stage index was similar among the treatments AIn, A/AIn, and A/In. Larvae fed exclusively on inert feed (treatment In) had lower larval stage index from the fifth day until the end of the experiment (Figure 1). Most of these larvae remained in stage IV from day 7 to 13 and during this period, larval stage index was lower than 5. From day 13 onward, larvae from treatment In showed heterogeneous development from stage V to VII.

Larvae consumed Artemia nauplii from zoea II onward and inert diet from zoea III onward (Figure 2). Zoea III and IV larvae consumed more live feed than inert diet. In treatments $\mathrm{A} / \mathrm{In}$ and $\mathrm{In}$, more than $80 \%$ of the larvae consumed inert feed when it was exclusive. Although not

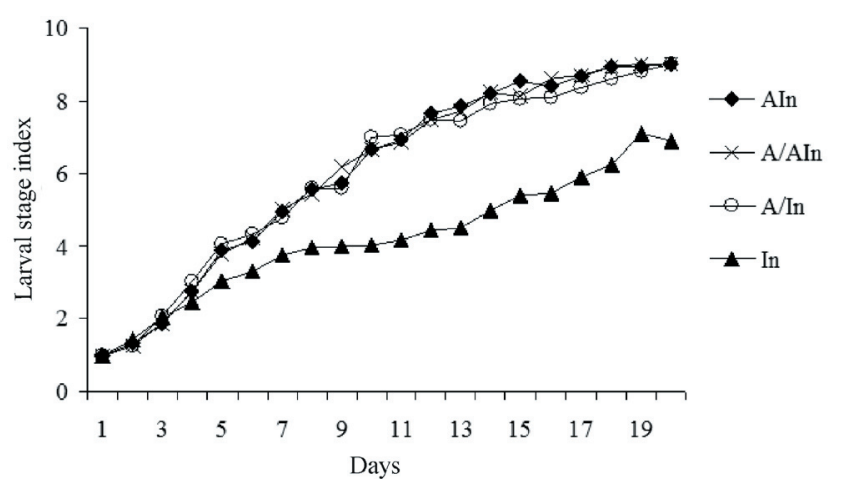

Figure 1 - Larval stage index of $M$. amazonicum larvae fed Artemia nauplii + inert diet during the entire larval cycle (AIn), Artemia nauplii for the entire larval cycle + inert diet from stage $\mathrm{V}$ onward (A/AIn), Artemia nauplii until stage IV + inert diet from stage IV onward (A/In), and only inert diet for the entire larval cycle (In).
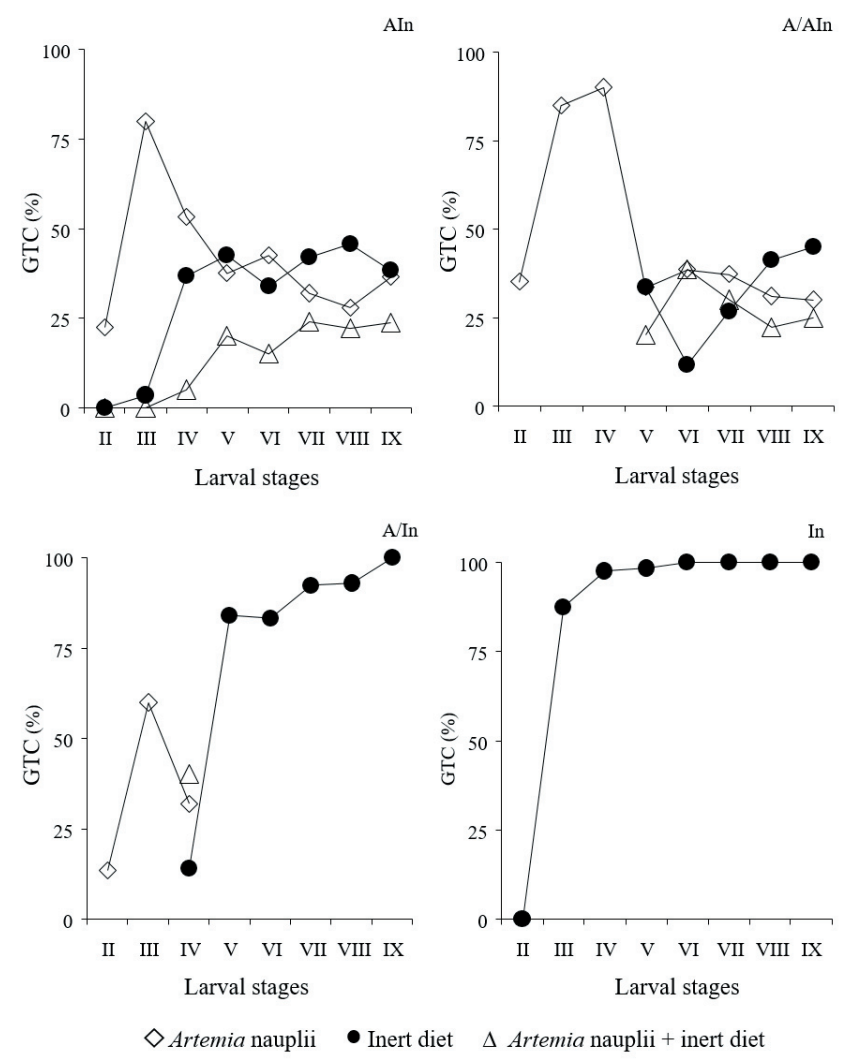

Figure 2 - Gastrointestinal tract content (CTC) of Artemia nauplii and inert diet in the digestive tract of M. amazonicum larvae at different larval stages that were fed Artemia nauplii + inert diet during the entire larval cycle (AIn), Artemia nauplii for the entire larval cycle + inert diet from stage V onward (A/AIn), Artemia nauplii until stage IV + inert diet from stage IV onward (A/In), and only inert diet for the entire larval cycle (In). 
quantified, yolk was abundant in zoea II and cannibalism was frequently observed inside tanks.

Survival and productivity significantly varied among treatments $(\mathrm{P}<0.01)$ (Figure 3). Mean values decreased from treatment AIn to A/AIn and from this to A/In. A very high mortality was observed in treatment In from stage $\mathrm{V}$ onward. There was significant correlation between survival $(\mathrm{r}=0.84 ; \mathrm{P}<0.05)$ and productivity $(\mathrm{r}=0.86 ; \mathrm{P}<0.05)$ with the number of days that larvae ate Artemia naupii. No significant difference was found among the treatments for weight gain by ANOVA $(\mathrm{P}>0.05)$ (Figure 3 ).

\section{Discussion}

Data showed that M. amazonicum larvae ate Artemia nauplii and inert diet from stages II and III onward, respectively. Larvae fed only inert diet showed retarded development and very low survival and metamorphosis after 20 days. The best survival and productivity were
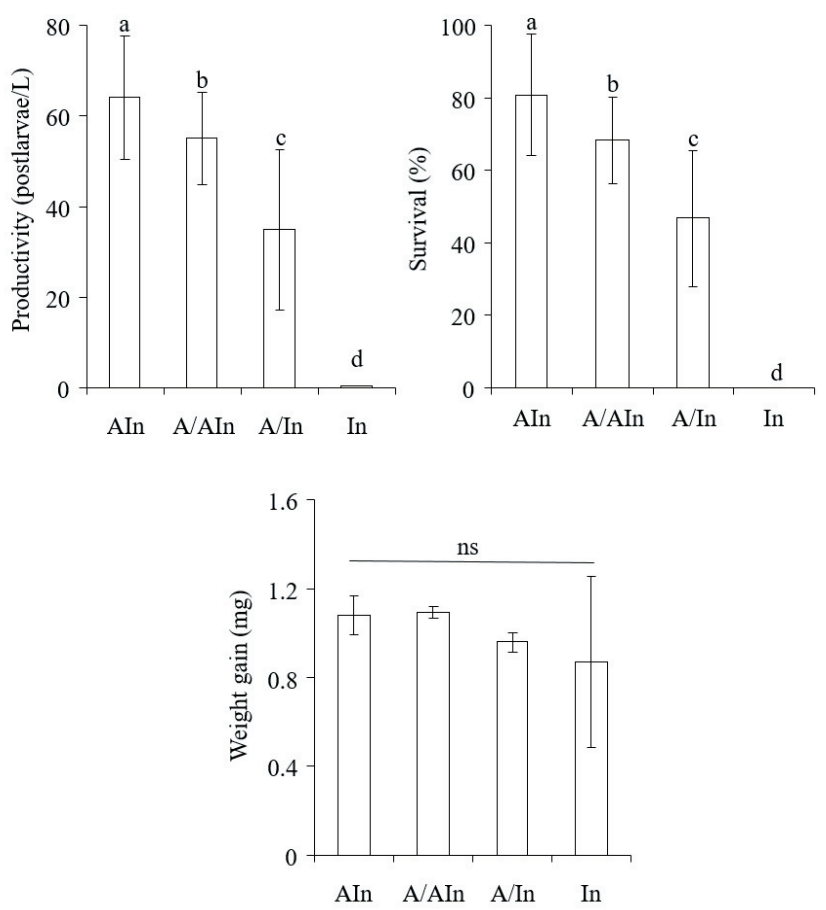

Different letters over bars indicate significant difference among treatments by $G$-test $(\mathrm{P}<0.01)$.

SD - standard deviation; ns - no significant.

Figure 3 - Survival, productivity, and weight gain (mean \pm SD) obtained for M. amazonicum larvae and postlarvae fed Artemia nauplii + inert diet during the entire larval cycle (AIn), Artemia nauplii for the entire larval cycle + inert diet from stage $\mathrm{V}$ onward (A/AIn), Artemia nauplii until stage IV + inert diet from stage IV onward (A/In), and only inert diet for the entire larval cycle (In). obtained by supplying a combination of Artemia nauplii and inert diet from stage II onward. Feeding larvae with Artemia throughout their developmental cycles, followed by the introduction of inert diet at stage $\mathrm{V}$, decreased survival and productivity, with an even higher reduction observed when Artemia was totally replaced by inert diet from zoea V onward. On the other hand, larval growth was not affected by the four feed management regimes tested.

The low feed intake in stage II is due to the large yolk reserves present at this stage, which supply metabolic requirements. This stage is facultatively lecithotrophic (Anger and Hayd, 2010) and larvae can save energy by avoiding eating. Previous experiments have showed that survival and productivity were very low when larvae were fed only Artemia nauplii throughout culture (Maciel and Valenti, 2014a). A similar result was obtained in the present study, when larvae were fed only inert diet. Conversely, the best performance was obtained when animals were fed Artemia + inert diet during the entire larval cycle. Therefore, a synergic effect arises when these two feeds are combined. They may have a complementary nutrient profile or mechanism to improve nutrient assimilation. Artemia may provide exogenous enzymes, which remain functional inside the gut of M. amazonicum, or stimulus to activate endogenous enzymes of larvae, increasing nutrient assimilation from inert diet (Maciel and Valenti, 2014a).

In treatment In, no Artemia was provided and larvae ate only inert diet; high mortality started from stage $\mathrm{V}$ onward. Macrobrachium amazonicum hatch with a large quantity of yolk reserves, enabling them to survive without feed up to stages IV or V (Araujo and Valenti, 2010). During this phase, a large mobilization of lipids is observed and larvae can live until two weeks (Anger and Hayd, 2010). High mortality was observed throughout the experiment from stage $\mathrm{V}$ onward, although the gut of more than $80 \%$ of larvae was full of feed. This indicates that nutrient profile of inert diet did not match the requirements of larvae or larvae could not assimilate such nutrients without the presence of Artemia nauplii. Perhaps, larvae that attained metamorphosis balanced their nutritional deficiencies by feeding on other larvae. Cannibalism is very common in M. amazonicum larvae and postlarvae and was observed in the present experiment.

Studies with $M$. rosenbergii also revealed difficulties in substituting live feed by inert diet during larval development (Lavens et al., 2000). These weaknesses are not due to nutritional deficiencies from artificial diets, but rather because of an undeveloped digestive system with 
a low concentration of proteolytic enzymes (Kamarudin et al., 1994; Kumlu and Jones, 1995). There are no studies on digestive enzymes of $M$. amazonicum larvae. Nevertheless, the foregut of the larvae undergoes diverse morphological changes during larval development (Queiroz et al., 2011).

Artemia is essential for $M$. amazonicum larval development, although the combination with inert diet increases survival and metamorphosis. A trend of gradual increase in values of these variables was observed from treatment In, then, treatment A/In, followed by A/AIn and AIn. In essence, survival and productivity (related with metamorphosed animals) increased with the time larvae were fed Artemia nauplii.

\section{Conclusions}

Macrobrachium amazonicum larvae are omnivorous and polytrophic, but live feed is essential in the first stages and act as a complementary diet in the last half of larval cycle. There is a potential for inert diet to partially replace Artemia in the last phase of development if the nutrient composition matches requirements of larvae. The combination of Artemia nauplii and inert diet during the entire larval cycle is the best management to maximize productivity.

\section{Acknowledgments}

The authors thank the Centro de Aquicultura of the Universidade Estadual Paulista (CAUNESP), Jaboticabal, SP, Brazil, for providing the Macrobrachium amazonicum larvae for this study. Authors thank also the Coordenação de Aperfeiçoamento de Pessoal de Nível Superior (CAPES) and Conselho Nacional de Desenvolvimento Científico e Tecnológico (CNPq) for financial support.

\section{References}

Alam, M. J.; Ang, K. J. and Begum, M. 1995. Replacement of Artemia with Moina micrura in the rearing of freshwater shrimp larvae. Aquaculture International 3:243-248.

Anger, K. and Hayd, L. 2009. From lecithotrophy to planktotrophy: ontogeny of larval feeding in the Amazon River prawn Macrobrachium amazonicum. Aquatic Biology 7:19-30.

Anger, K. and Hayd, L. A. R. 2010. Feeding and growth in early larval shrimp, Macrobrachium amazonicum, from the Pantanal, Southwestern Brazil. Aquatic Biology 9:251-261.

Araujo, M. C. and Valenti, W. C. 2007. Feeding habit of the Amazon river prawn Macrobrachium amazonicum larvae. Aquaculture 265:187-193.

Araujo, M. C. and Valenti, W. C. 2010. Efeito de baixas salinidades sobre larvas de Macrobrachium amazonicum (Crustacea, Palaemonidae) submetidas à inanição. Magistra 22:191-197.
Barros, H. P. and Valenti, W. C. 2003. Food intake of Macrobrachium rosenbergii during larval development. Aquaculture 216:165-176.

Guest, W. C. 1979. Laboratory life history of the palaemonid shrimp Macrobrachium amazonicum (Heller) (Decapoda, Palaemonidae). Crustaceana 37:141-152.

Kamarudin, M. S.; Jones, D. A.; Vay, L. and Abidin, A. Z. 1994. Ontogenetic change in digestive enzyme activity during larval development of Macrobrachium rosenbergii. Aquaculture 123:323-333.

Kovalenko, E. E.; D’Abramo, L. R.; Ohs, C. L. and Buddington, R. K. 2002. A successful microbound diet for the larval culture of freshwater prawn Macrobrachium rosenbergii. Aquaculture 210:385-395.

Kumlu, M. and Jones, D. A. 1995. Feeding and digestion in the caridean shrimp larva Palaemon elegans Rathke and Macrobrachium rosenbergii (De Man) (Crustacea: Palaemonidae) on live and artificial diets. Aquaculture Nutrition 1:3-12.

Kutty, M. N.; Herman, F. and Le Menn, H. 2000. Culture of other prawn species. p.393-410. In: Freshwater prawn culture: The farming of Macrobrachium rosenbergii. New, M. B. and Valenti, W. C., eds. Blackwell Science, Oxford.

Lavens, P.; Thongrod, S. and Sorgeloos, P. 2000. Larval prawn feeds and the dietary importance of Artemia. p.91-110. In: Freshwater prawn culture: The farming of Macrobrachium rosenbergii. New, M. B. and Valenti, W. C., eds. Blackwell Science, Oxford.

Loya-Javellana, G. 1989. Ingestion saturation and growth responses of Penaeus monodon larvae to food density. Aquaculture 81:329-336.

Maciel, C. R. and Valenti, W. C. 2014a. Assessing the potential of partial replacing of artemia by practical inert diet in the larviculture of the Amazon river prawn. Boletim do Instituto de Pesca 40:69-78.

Maciel, C. R. and Valenti, W. C. 2014b. Effect of tank colour on larval performance of the Amazon River prawn Macrobrachium amazonicum. Aquaculture Research 45:1041-1050.

Mallasen, M. and Valenti, W. C. 1998. Comparison of artificial and natural, new and reused, brackish water for the larviculture of the freshwater prawn Macrobrachium rosenbergii in a recirculating system. Journal of the World Aquaculture Society 29:345-350.

Manzi, J. J.; Maddox, M. B. and Sandifer, P. A. 1977. Algal supplement enhancement of Macrobrachium rosenbergii (De Man) larviculture. Proceedings of the World Mariculture Society 8:207-223.

Marques, H. L. A. and Moraes-Valenti, P. 2012. Current status and prospects of farming the giant river prawn (Macrobrachium rosenbergii (De Man 1879) and the Amazon River prawn Macrobrachium amazonicum (Heller 1862) in Brazil. Aquaculture Research 43:84-992.

Moraes-Valenti, P. and Valenti, W. C. 2010. Culture of the Amazon river prawn Macrobrachium amazonicum. p.485-501. In: Freshwater prawns: Biology and farming. New, M. B.; Valenti, W. C.; Tidwell, J. H.; D’Abramo, L. R. and Kutty, M. N., eds. WileyBlackwell, Oxford

Queiroz, L.; Abrunhosa, F. and Maciel, C. R. 2011. Ontogenesis and functional morphology of the digestive system of the freshwater prawn, Macrobrachium amazonicum (Heller, 1862) (Decapoda, Palaemonidae). Revista Brasileira de Zoologia 28:395-402.

Sokal, R. R. and Rohlf, F. J. 1995. Biometry: the principles and practice of statistics in biological research. 3rd ed. W.H. Freeman and Company, New York.

Solorzano, L. 1969. Determination of ammonia in natural waters by the phenylhypochlorite method. Limnology and Oceanography 14:799-801.

Sorgeloos, P. and Léger, P. H. 1992. Improved larviculture outputs of marine fish, shrimp and prawn. Journal of the World Aquaculture Society 23:251-264. 
Strickland, J. D. H. and Parsons, T. R. 1972. A practical handbook of seawater analysis. Fisheries Research Board of Canada, Ottawa.

Valenti, W. C. 2007. Current status of freshwater prawn culture in Brazil. p.105-110. In: Freshwater Prawns. Advances in biology, aquaculture and marketing. Nair, C. M.; Nambudiri, D. D.; Jose, S.; Sankaran, T. M.; Jayachandra, N, K. V. and Salin, K. R., eds.
Proceedings of the International Symposium on Freshwater Prawns, 20-23 August 2003, Kochi, Kerala, India. Allied Publishers, New Delhi, India.

Valenti, W. C.; Daniels, W. H.; New, M. B. and Correia, E. 2010. Hatchery systems and management. p.55-85. In. Freshwater prawns: Biology and farming. New, M. B., Valenti, W. C., Tidwell, J. H., D'Abramo, L. R. and Kutty, M. N., eds. Wiley-Blackwell, Oxford. 